\title{
Application of Chemical Crystallization Circulating Pellet Fluidized Beds for Softening and Saving Circulating Water in Thermal Power Plants
}

\author{
Ruizhu Hu ${ }^{1,2}$, Tinglin Huang ${ }^{1,2, *}$, Tianwei Wang ${ }^{3}$, Huixin Wang ${ }^{3}$ and Xiao Long ${ }^{4}$ \\ 1 Key Laboratory of Northwest Water Resource, Environment and Ecology, MOE, Xi'an University of \\ Architecture and Technology, Xi'an 710055, China; www_lonely_com@163.com \\ 2 Shaanxi Key Laboratory of Environmental Engineering, Xi'an University of Architecture and Technology, \\ Xi'an 710055, China \\ 3 Department of Production and Technology, Hebei Guohua Dingzhou Power Generation Co., Ltd., \\ Dingzhou 070334, China; luckyone345@126.com (T.W.); SDtangzhch@163.com (H.W.) \\ 4 Department of Physical and Chemical Detection and Analysis Department, HEBEI Ji-Yan Energy Science \\ and Technology Research Institute Co., Ltd., Shijiazhuang 050001, China; paul8122@126.com \\ * Correspondence: huangtinglin@xauat.edu.cn; Tel.: +86-29-8220-1038
}

Received: 13 October 2019; Accepted: 13 November 2019; Published: 19 November 2019

\begin{abstract}
The circulating pellet fluidized bed (CPFB) softening method is a highly efficient and environmentally friendly softening technology that can be used to reduce water hardness during the pretreatment process of circulating water in thermal power plants. The performance of chemical crystallization $\mathrm{CPFB}$ reactors was tested for increasing the concentration ratio and softening the circulating water in a thermal power plant in Dingzhou, Hebei. The results show that usage of CPFB reactors removed water hardness and $\mathrm{Ca}^{2+}$ ions with efficiencies exceeding $60 \%$ and $90 \%$, respectively. The size of the particles discharged from the reactors was approximately $1-3 \mathrm{~mm}$, and the content of $\mathrm{CaO}$ in these particles was found to be greater than $50 \%$. All the discharged particles were reused in the desulfurization system in the power plant. The operational cost of the CPFB system is US\$0.074 per cubic meter of water. After adopting the proposed CPFB softening method in the Dingzhou Power Plant, the concentration ratio of the circulation cooling water was increased from 4.5 to more than 9. In addition, the amount of replenished water and sewage discharge were both reduced by $150 \mathrm{~m}^{3} / \mathrm{h}$, and the amount of scale inhibitor used in the system was reduced by more than $30 \%$. These improvements contribute to approximately US $\$ 200,000$ in annual savings in the power plant. In summary, the CPFB softening method demonstrated a high hardness removal rate, strong economic benefits, and remarkable environmental and social benefits. Therefore, this method seems ideal for softening replenished circulating cooling water, increasing the concentration ratio of the water and achieving zero liquid discharge (ZLD) in thermal power plants.
\end{abstract}

Keywords: circulating pellet fluidized bed; thermal power plant; circulating cooling water; concentration ratio; zero liquid discharge

\section{Introduction}

Thermal power generation is the primary mode of power generation in China. The installed capacity and power generation of thermal power plants in China account for approximately $80 \%$ and $78.72 \%$ of the total installed capacity and power generation in the country, respectively [1].

Thermal power plants consume large amounts of fresh water during the power generation process [2]. It has been reported that the water consumption of thermal power plants accounts for $11 \%$ of the total industrial water consumption in the country, and the circulating cooling water system of 
thermal power plants itself accounts for $84 \%$ of the water consumption of thermal power plants $[3,4]$. Therefore, reducing the consumption of circulating cooling water is of great significance for realizing zero liquid discharge in power plants in accordance with the national zero liquid discharge policy. The amount of circulating cooling water used can be reduced by changing the water source and reducing freshwater consumption [1]. For example, Yi et al. proposed using reclaimed water as circulating cooling water to reduce freshwater consumption and improve the utilization efficiency of water resources [5]. Reductions in the amount of circulating cooling water used can also be realized by improving the concentration ratio and utilization rate of the circulating water. For example, in a study carried out by Rahmani et al., the authors demonstrated that increasing the concentration ratio of circulating water from 6.5 to 9 can reduce annual freshwater consumption by $1.1 \times 10^{6} \mathrm{~m}^{3}$. Such an approach can greatly reduce the amount of water used for replenishing circulating water as well as that of wastewater discharge [6].

Fouling is the first problem that needs to be solved to improve the concentration ratio of circulating water. Currently, fouling issues are primarily resolved by either adding chemical agents or using sulfuric acid as a scale inhibitor. Ochoa et al. experimentally studied the performance of a specific type of corrosion and scale inhibitor by adding these chemical inhibitors to a circulating water system [7]; it is common to use scaling inhibitors like phosphates, polyphosphates, and organophosphonates, as well as corrosion inhibitors such as zinc sulphate and azoles [8]. Rahmani et al. analyzed the scale-inhibiting effect and the associated working principle of adding sulfuric acid as a scale inhibitor in the fluid during the pretreatment process for circulating water replenishment [8]. Sulfuric acid has normally been used for carbonate calcium scale control in cooling water systems, as acid treatment converts calcium bicarbonate to more stable and soluble calcium sulfate. Although these two methods can effectively prevent the formation of calcium carbonate scales, failing to remove calcium carbonate from the circulating water results in very high hardness in the wastewater generated in subsequent processes. Therefore, it becomes more challenging to fully treat wastewater in later stages. Adding lime or sodium carbonate directly is an effective way to soften water, which is a different method from those mentioned above and can reduce the hardness of water. However, this method will produce a lot of sludge, and the operation is complex and equipment fouling occurs easily. Thus, this pretreatment method is not suitable for softening of circulating water $[9,10]$.

The chemical crystallization circulating pellet fluidized bed (CPFB) softening method is a highly efficient and environmentally friendly softening technology that can be used to reduce water hardness during the pretreatment process of the circulating water. For example, Hu et al. applied CPFBs to soften groundwater and determined the operating parameters under specific water quality conditions [11]. They further studied the growth rate of the particles in Amsterdam's crystallization fluidized bed reactor, as well as the relationship between the growth rate of the bed, rising flow rate, particle size, and supersaturation conditions on a pilot scale. A mathematical model for calculating the corresponding parameters is also provided in their study [12]. Tang et al. applied chemical-crystallization CPFBs to treat wastewater in a thermal power plant and verified their water-softening effect [13].

In summary, CPFBs can be used in the softening pretreatment of circulating water to remove calcium carbonate and prevent scale formation, as well as to simplify subsequent wastewater treatment processes. As an engineering case of circulating-water saving technology applied in a large-scale power plant, this paper provides important engineering data and information for the subsequent application of the proposed technology in industrial water circulation systems. In this study, the softening performance of CPFBs was studied under production testing conditions on the circulating water used in the Guohua Dingzhou Power Generation Co., Ltd., Hebei, China. Additionally, the impact of water quality was explored on improving the concentration ratio of circulating water after softening pretreatment under laboratory conditions. 


\section{Materials and Methods}

\subsection{Material}

In this study, the production tests were performed on the replenishment of circulating water at Guohua Dingzhou Power Generation Co., Ltd. Water was sampled directly from the reservoir for our tests. Table 1 summarizes the water quality parameters. A $\mathrm{NaOH}$ solution with a concentration of $30 \%$ was dispersed in the test water. The $\mathrm{pH}$ value of the test water was tuned using a $\mathrm{H}_{2} \mathrm{SO}_{4}$ solution with a concentration of $92 \%$. Crystal seed size ranged from 0.4 to $0.6 \mathrm{~mm}$, and their density was $3.93 \mathrm{~g} / \mathrm{cm}^{3}$.

Table 1. Summary of the water quality parameters of the circulating water.

\begin{tabular}{ccccccc}
\hline $\mathbf{p H}$ & $\begin{array}{c}\text { Turbidity } \\
(\mathbf{N T U})\end{array}$ & $\begin{array}{c}\text { Total Alkalinity } \\
(\mathbf{m M})\end{array}$ & $\begin{array}{c}\mathrm{HCO}_{3}{ }^{-} \\
(\mathbf{m M})\end{array}$ & $\begin{array}{c}\text { Total Hardness } \\
(\mathbf{m M})\end{array}$ & $\begin{array}{c}\mathrm{Ca}^{2+} \\
(\mathbf{m M})\end{array}$ & $\begin{array}{c}\mathbf{M g}^{2+} \\
(\mathbf{m M})\end{array}$ \\
\hline $7.5-7.7$ & $<1$ & $3.1-3.5$ & $3.1-3.5$ & $2.3-2.75$ & $1.6-1.75$ & $0.7-1.0$ \\
\hline
\end{tabular}

\subsection{Full-Scale Experimental System and Process Description}

Figure 1 shows a flow chart of the circulating-water replenishment and softening system under consideration. This system is designed to handle a flow rate of $1200 \mathrm{~m}^{3} / \mathrm{h}$ using three circulating pellet fluidized bed (CPFBs) reactors with a diameter of $2400 \mathrm{~mm}$ each. Each reactor is designed to perform water treatment at a flow rate of $400 \mathrm{~m}^{3} / \mathrm{h}$. The system also includes a set of lye- and acid-dosing systems, one set of seed-dosing systems, and one set of particle-collecting systems. The total area of the workshop is $170 \mathrm{~m}^{2}$.

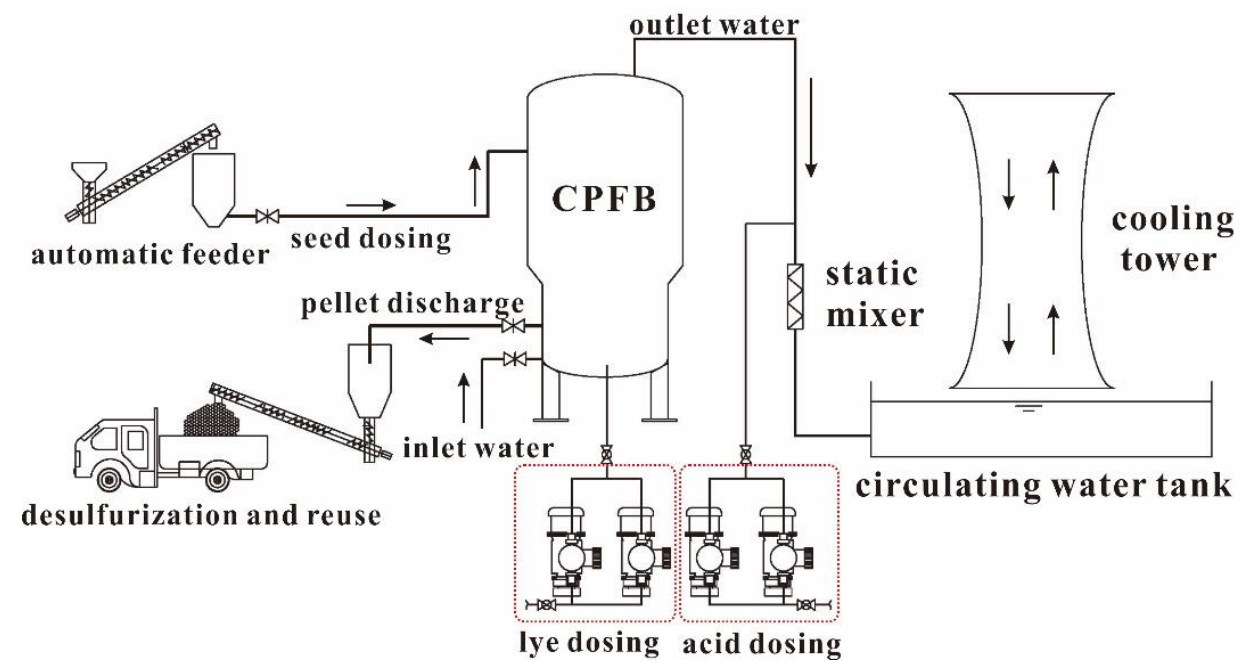

Figure 1. Flow chart of the circulating pellet fluidized bed softening system.

To replenish the circulating water, fresh water is first injected into the CPFB system and then discharged into the circulating-water pool, accompanied by the disposal of calcium carbonate particles. Details of the operating procedure and reaction processes can be found in existing literature [11]. The calcium carbonate particles disposed by the system are transported directly from the collection tank to the power plant's desulfurization system to be used as a desulfurizer.

The water discharged from the CPFB system after $\mathrm{pH}$ adjustment was used to perform dynamic scale-inhibition simulation tests and scale-inhibition reagent-reduction tests in the laboratory. The test apparatus is shown in Figure 2. The test methods and evaluation standards used were determined based on Chinese chemical industry standards [14,15]. During the entire test process, the $\Delta B$ is calculated and kept to less than 0.2:

$$
\Delta B=K_{C l^{-}}-K_{C a^{2+}} \leq 0.2
$$


where $\mathrm{K}_{\mathrm{Cl}}$ is the concentration of chloride ion, and $\mathrm{K}_{\mathrm{Ca}^{2+}}$ is the concentration ratio of calcium hardness.

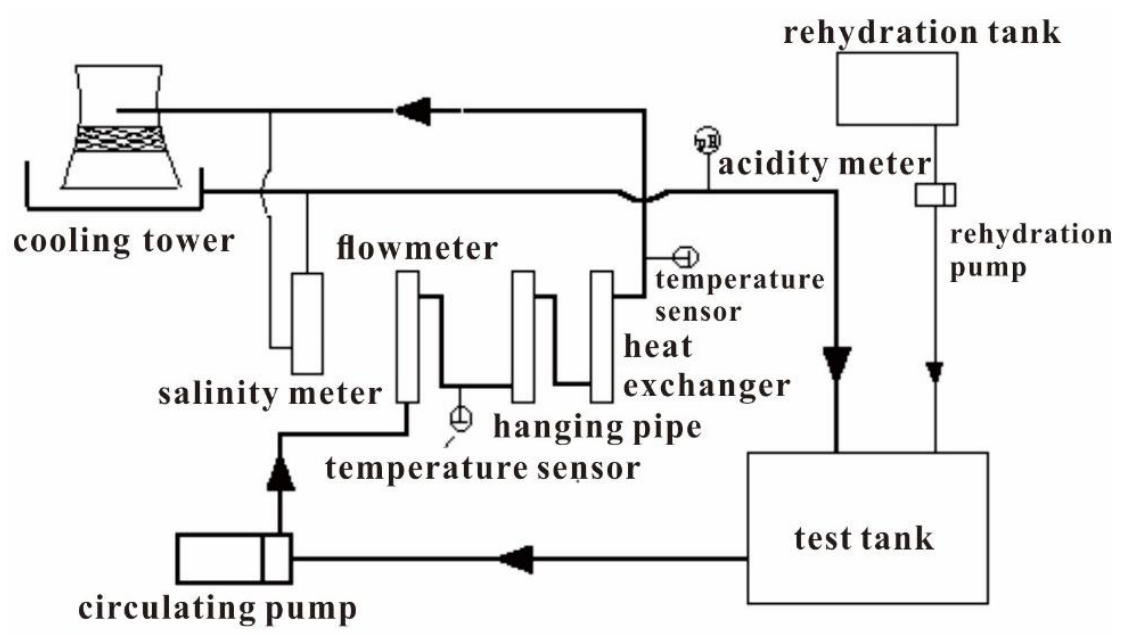

Figure 2. Flow chart of the dynamic scale-inhibition simulation test.

Finally, a corrosion test was performed using the water sample at a high concentration ratio. The corresponding test methods and evaluation standards were determined based on Chinese national standards [16]. The determination of corrosion rate (B) is expressed as the annual corrosion rate $(\mathrm{mm} / \mathrm{a})$, and the calculation method is as follows. According to the standards, the corrosion rate of all kinds of stainless-steel equipment used in circulating cooling water system should be of less than $0.005 \mathrm{~mm} / \mathrm{a}$ :

$$
B=3650 \frac{G}{A T \rho}
$$

where $\mathrm{G}$ is the weight loss of test piece $(\mathrm{g}), \mathrm{T}$ is the test time $(\mathrm{d}), \mathrm{A}$ is the area of test piece $\left(\mathrm{cm}^{2}\right)$, and $\rho$ is the density of the metal $\left(\mathrm{g} / \mathrm{cm}^{3}\right)$.

\subsection{Analytical Methods}

The total hardness and concentration of $\mathrm{Ca}^{2+}$ and $\mathrm{Mg}^{2+}$ were determined via the EDTA titration method [17]. Particle size was determined via the ASTM screening method [18]. The pH value of the water was measured using both an online and real-time $\mathrm{pH}$ meter $(\mathrm{HACH} \mathrm{sc} 200)$ as well as a handheld portable $\mathrm{pH}$ meter (HACH HQ11d). The composition of the particles emitted from the system was characterized using an inductively coupled plasma optical emission spectrometer (Optima 8000, Perkin Elmer), an electronic balance (ME104/02, Mettler Toledo), and a microwave digestion instrument (Multiwave PRO, Anton-Paar). A scale-inhibition tester [14] and a ZJ-type corrosion rate tester [16] were used to measure scale inhibition.

\section{Results and Discussion}

\subsection{Softening Performance of the CPFBs for Replenishment of Circulating Water}

\subsubsection{Efficiency of CPFBs for Reducing Hardness}

Figure 3 shows the softening effects of the three CPFBs on the discharge water under different time and flow rate conditions. All three fluidized beds were operating at a load of $50-110 \mathrm{~m} / \mathrm{h}$. As shown in Figure 3, the total hardness of the discharged water could reach as much as $1.4 \mathrm{mM}$, and the fluidized beds could reduce total hardness by $40-50 \%$. In addition, the concentration of $\mathrm{Ca}^{2+}$ ions was approximately $0.4 \mathrm{mM}$, and the fluidized beds could remove up to $90 \%$ of the $\mathrm{Ca}^{2+}$ ions. It can be seen from the figure that the total hardness and $\mathrm{Ca}^{2+}$ ions concentration in the water increased slightly after adjusting the $\mathrm{pH}$ with acid. This is because a small volume of fine calcium carbonate particles 
flows out with the water during the crystallization process and these therefore fail to crystallize on the surface of the seed crystal. However, the addition of sulfuric acid causes the calcium carbonate to dissolve, which results in a slight increase in total hardness and $\mathrm{Ca}^{2+}$ ion concentration [10].

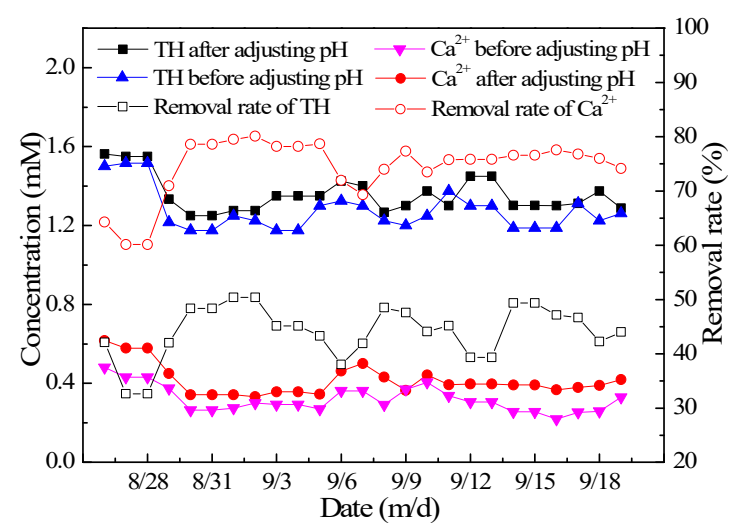

(a) CPFB \#1

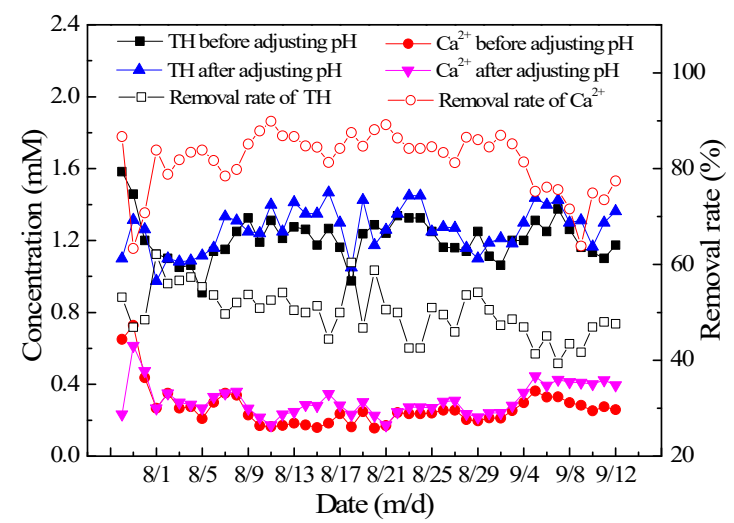

(b) CPFB \#2

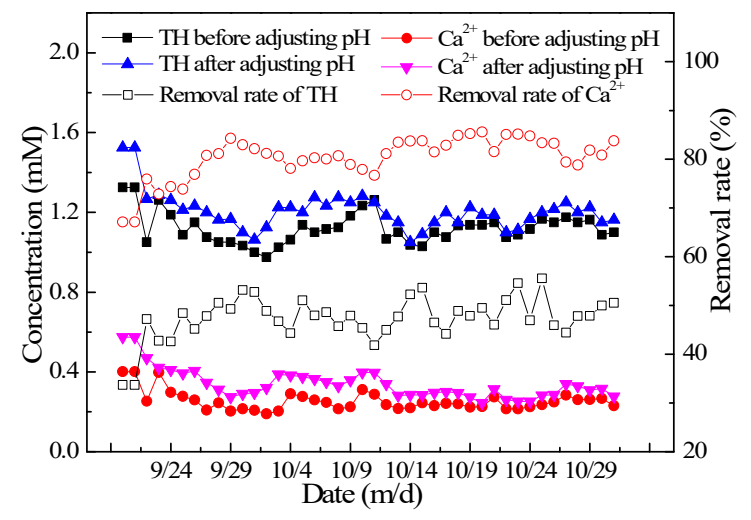

(c) CPFB \#3

Figure 3. Hardness and $\mathrm{Ca}^{2+}$ ion removal performance of circulating pellet fluidized beds (CPFBs). ((a)-hardness and $\mathrm{Ca}^{2+}$ ion removal performance of circulating pellet fluidized bed(CPFB) \#1 at different dates; (b)-hardness and $\mathrm{Ca}^{2+}$ ion removal performance of circulating pellet fluidized bed(CPFB) \#2 at different dates; (c)-hardness and $\mathrm{Ca}^{2+}$ ion removal performance of circulating pellet fluidized bed(CPFB) \#3 at different dates).

Because the $\mathrm{HCO}_{3}{ }^{-}$ion content in the water was higher than the $\mathrm{Ca}^{2+}$ ion content, total hardness and the removal efficiency of $\mathrm{Ca}^{2+}$ ions are directly related to the amount of $\mathrm{NaOH}$ added to the water. A greater $\mathrm{NaOH}$ dosage results in higher removal rates, and therefore higher operating costs. As shown in Figure 4, the total cost of the chemicals $\left(\mathrm{NaOH}+\mathrm{H}_{2} \mathrm{SO}_{4}\right)$ per ton of water ranges between $\$ 0.06$ and $\$ 0.10$ when the removal rate of $\mathrm{Ca}^{2+}$ varies between $75 \%$ and $90 \%$. During actual operation, the hardness removal effect must be adjusted to reduce costs [11]. 


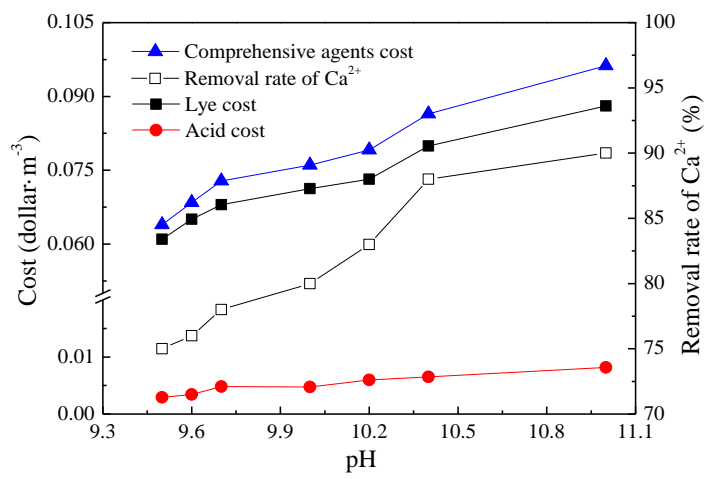

Figure 4. Dosage and cost of the chemicals used in the system under different $\mathrm{pH}$ conditions.

\subsubsection{Efficiency of CPFBs for Reducing Alkalinity}

Figure 5 shows the alkalinity removal performance of the three CPFBs on the discharged water under different time and flow rate conditions. All three fluidized beds were operated at a load of $50-110 \mathrm{~m} / \mathrm{h}$. A conversion process between $\mathrm{HCO}_{3}{ }^{-}$ions and $\mathrm{CO}_{3}{ }^{2-}$ ions in water can observed from the figure corresponding to before and after the $\mathrm{pH}$ was adjusted by the addition of acid. The $\mathrm{HCO}_{3}{ }^{-}$ ion content of the discharged water ranged between 2 and $3 \mathrm{mM}$, and $30 \%-40 \%$ of the $\mathrm{HCO}_{3}{ }^{-}$ions were removed by the fluidized beds. The amount of $\mathrm{HCO}_{3}{ }^{-}$ions removed from water is proportional to the amount of $\mathrm{Ca}^{2+}$ ions removed and is in accordance with the theoretical chemical formulation.

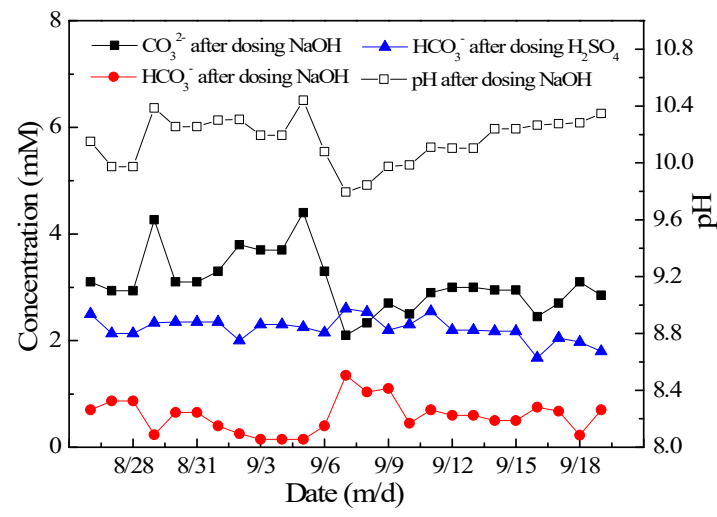

(a) CPFB \#1

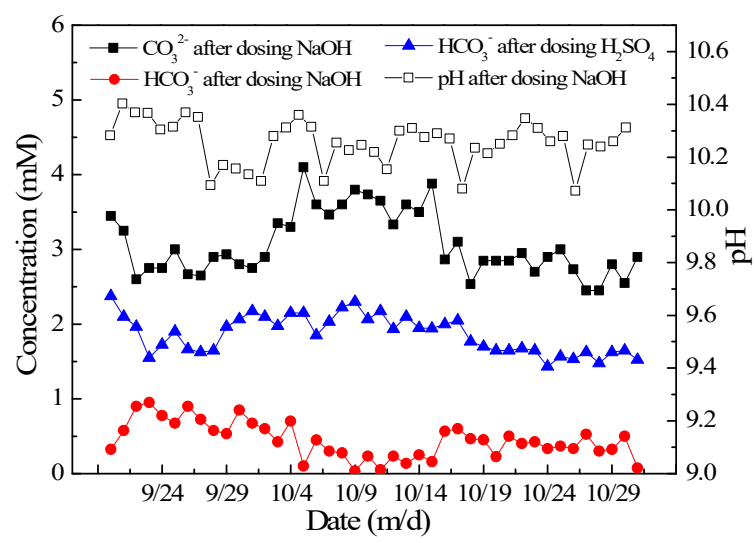

(c) CPFB \#3

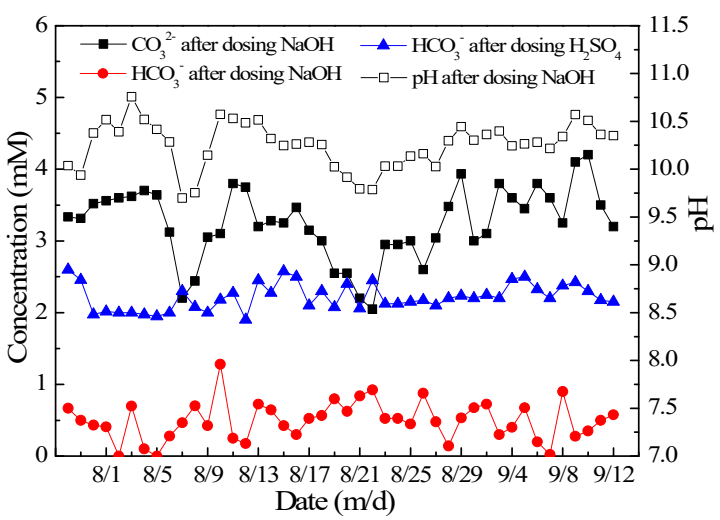

(b) CPFB \#2

Figure 5. Alkalinity removal performance of the CPFBs. ((a)-alkalinity removal performance of the circulating pellet fluidized bed(CPFB) $1 \#$ at different dates; (b)-alkalinity removal performance of the circulating pellet fluidized bed(CPFB) $2 \#$ at different dates; (c)-alkalinity removal performance of the circulating pellet fluidized bed(CPFB) $3 \#$ at different dates). 
As shown in Figure 5, $\mathrm{HCO}_{3}{ }^{-}$ions first reacts with the $\mathrm{NaOH}$ in the water to form $\mathrm{CO}_{3}{ }^{2-}$ ions and water. The majority of the $\mathrm{CO}_{3}{ }^{2-}$ ions then react with the $\mathrm{Ca}^{2+}$ ions in the water to form calcium carbonate $\left(\mathrm{CaCO}_{3}\right)$, which crystallizes on the surface of the seed crystal. A small volume of calcium carbonate flows out with the water before it can begin to crystallize, and a part of the $\mathrm{CO}_{3}{ }^{2-}$ ions will remain in the water, making it have a high $\mathrm{pH}$. This is because the concentration of $\mathrm{CO}_{3}{ }^{2-}$ ions reaches the solubility product constant of calcium carbonate during its formation. Because the amount of $\mathrm{Ca}^{2+}$ ions in the water is limited, the $\mathrm{CO}_{3}{ }^{2-}$ ions are not consumed completely. After adding $\mathrm{H}_{2} \mathrm{SO}_{4}$ to the water, the $\mathrm{CO}_{3}{ }^{2-}$ ions are converted into $\mathrm{HCO}^{3-}$ ions again, causing the $\mathrm{pH}$ of the water to drop to between 7 and 8 . Owing to the high residual alkalinity of the water, there still exists a risk of scaling at high concentration ratios. Therefore, it is necessary to further add a small amount of $\mathrm{H}_{2} \mathrm{SO}_{4}$ to prevent scaling in the subsequent circulating water system.

\subsubsection{Composition Analysis of Particles Discharged from the CPFBs}

The only by-product of the circulating fluidized bed softening system is crystallized calcium carbonate particles, which can be used in a variety of applications [19]. One example of application is as a desulfurizer in the desulfurization systems in power plants. During desulfurization, the desulfurization agent, $\mathrm{CaCO}_{3}$, decomposes into $\mathrm{CaO}$, which reacts with sulfur dioxide to form calcium sulfate [20]. Therefore, there are strict requirements on the $\mathrm{CaO}$ content in the desulfurizer particles.

Figure 6 shows a scanning electron microscopy (SEM) image of the particles discharged from the system after about 20 days of equipment operation, and their size is usually approximately 1.0-3.0 mm at the time of discharge [21]. Via testing and analysis, the content of $\mathrm{CaO}$ in the particles generated from the CPFBs in the Dingzhou Power Plant was found to be $51.10 \%$, as shown in Table 2. This content satisfies the minimal $\mathrm{CaO}$ content requirement of $50 \%$ in the particles intended for use as desulfurizer in the Dingzhou Power Plant [22] and can therefore be re-used in the desulfurization systems in the plant. Since mid-September 2018, the particles produced by the CPFBs have been re-used in the desulfurization system in the Dingzhou Power Plant, thus achieving zero emissions in the entire softening system.

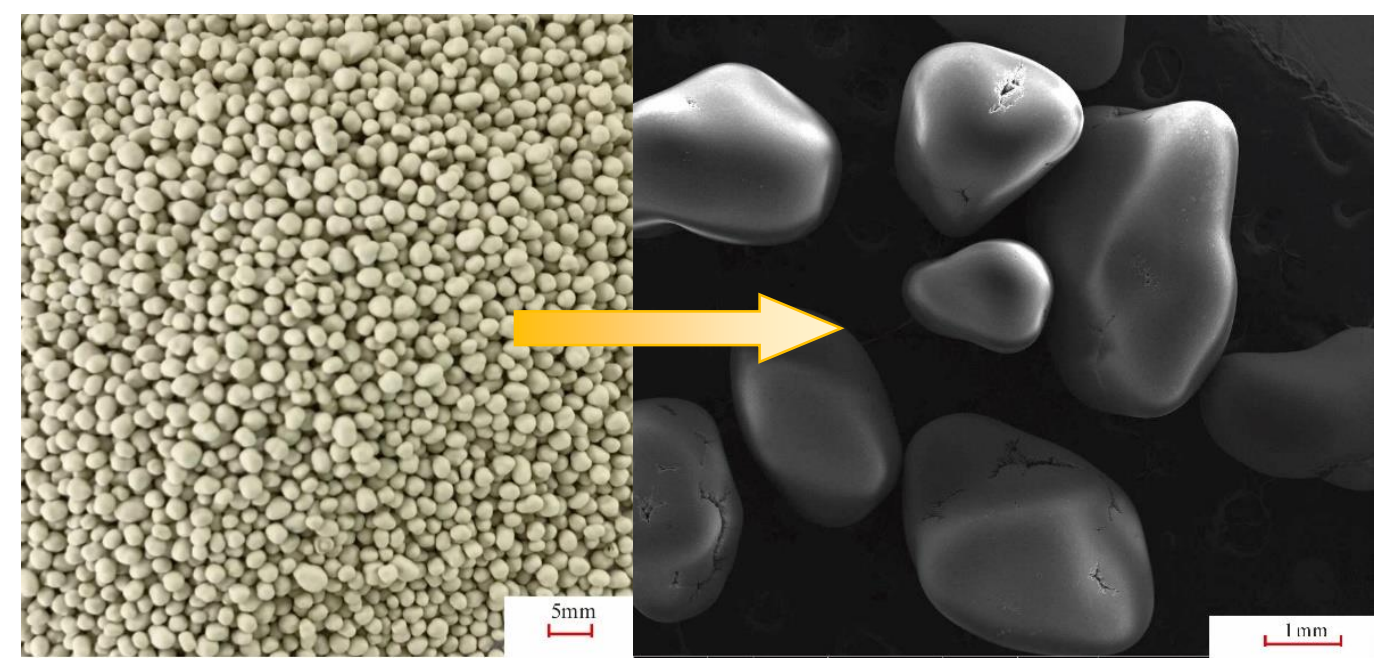

Figure 6. SEM image of the particles discharged from the system.

Table 2. Composition analysis results of the particles generated by the CPFB.

\begin{tabular}{cccccccc}
\hline \multirow{2}{*}{ Items } & $\mathrm{MgO}$ & $\mathrm{Al}_{2} \mathrm{O}_{3}$ & $\mathrm{SiO}_{2}$ & $\mathrm{~K}_{2} \mathrm{O}$ & $\mathrm{MnO}_{2}$ & $\mathrm{Fe}_{2} \mathrm{O}_{3}$ & $\mathrm{CaO}$ \\
\cline { 2 - 7 } & \multicolumn{7}{c}{ (Determined Based on the Oxide Product of Different Elements) } \\
\hline Analysis results & $0.74 \%$ & $0.07 \%$ & $2.99 \%$ & $0.09 \%$ & $0.06 \%$ & $1.33 \%$ & $51.10 \%$ \\
\hline
\end{tabular}




\subsection{Application of a CPFB System for Water Saving and Emission Reduction in Power Plants}

\subsubsection{Dynamic Simulation Test on the Circulating Water}

Increasing the concentration ratio of circulating water has been identified as an effective means for saving water and reducing emission in the circulating water systems of power plants [1,6]. To further investigate this approach, the dynamic scale-inhibition test was performed first using the water discharged from the CPFB system as the target sample. Based on the test results, a corrosion test was conducted using rotating coupons in order to optimize the production control parameters. The results of the dynamic scale-inhibition test are shown in Table 3.

Table 3. The results of dynamic scale-inhibition test.

\begin{tabular}{|c|c|c|c|c|c|c|}
\hline Water Sample & $\mathbf{K}_{\text {limit }}$ & $85 \% K_{\text {limit }}$ & $\begin{array}{c}\mathrm{Cl}^{-} \text {limit } \\
(\mathrm{mg} / \mathrm{L})\end{array}$ & $\begin{array}{c}\mathrm{Ca}^{2+}{ }_{\text {limit }} \\
(\mathrm{mg} / \mathrm{L})\end{array}$ & $\Delta \mathrm{B}$ & Note \\
\hline $\begin{array}{c}\text { Water } \\
\text { discharged from } \\
\text { the CPFBR } \\
\text { system }\end{array}$ & 10.82 & 9.20 & 238 & 92.58 & -0.20 & $\begin{array}{l}\text { Chemicals were added } \\
\text { to the water sample up } \\
\text { to a concentration of } \\
8.5 \mathrm{mg} / \mathrm{L} \text {; acid was } \\
\text { added to the water } \\
\text { sample to control the } \\
\text { p-alkalinity }(\leq 1.0 \mathrm{mM})\end{array}$ \\
\hline
\end{tabular}

As shown in Table 3, scale and corrosion inhibitors were added to the water discharged from the CPFB system in the Dingzhou Power Plant to obtain a concentration of $8.5 \mathrm{mg} / \mathrm{L}$. In addition, the phenolphthalein alkalinity (p-alkalinity) of the water was maintained below $1.0 \mathrm{mM}$ by adding sulfuric acid to the circulating water. These two approaches can prevent the formation of scales at a concentration ratio ( $\left.\mathrm{K}_{\text {limit }}\right)$ as high as 10.82 . Even after multiplying by a safety factor of 0.85 , a safety concentration ratio of 9.20 is attained. At such a high concentration ratio, the corrosion test was conducted and the corrosion rate of TP316L stainless steel was $0.0005 \mathrm{~mm} / \mathrm{a}$ as calculated by Equation (2), which satisfies the corrosion rate requirements of stainless-steel equipment $[15,23]$. Therefore, these tests can be used to determine effective circulating water control parameters for power plant operation, as shown in Table 4.

Table 4. Suggested control parameters for circulating water.

\begin{tabular}{ccccccc}
\hline Indicator & $\begin{array}{c}\text { Concentration } \\
\text { Ratio }\end{array}$ & $\begin{array}{c}\text { Calcium Ion } \\
(\mathbf{m g} / \mathbf{L})\end{array}$ & $\begin{array}{c}\text { Hardness } \\
(\mathbf{m M})\end{array}$ & $\begin{array}{c}\text { P-Alkalinity } \\
(\mathbf{m M})\end{array}$ & $\begin{array}{c}\text { Total Alkalinity } \\
(\mathbf{m M})\end{array}$ & pH \\
\hline $\begin{array}{c}\text { Circulating } \\
\text { water }\end{array}$ & $\leq 9.20$ & $\leq 77.28$ & $\leq 20.08$ & $\leq 1.0$ & $\leq 6.6$ & $\leq 8.75$ \\
\hline
\end{tabular}

\subsubsection{Effect of Water Discharged from Circulating Pellet Fluidized Bed on Dosage of Scale Inhibitors}

A scale-inhibitor reduction test was performed on water discharged from the CPFB system in the Dingzhou Power Plant. The test results are shown in Table 5. After adding a corrosion and scale inhibitor to the circulating water up to a concentration of $8.5 \mathrm{mg} / \mathrm{L}$, the corrosion rate of TP316L stainless steel was determined to be $0.0003 \mathrm{~mm} / \mathrm{a}$ as calculated by Equation (2) at a safety concentration ratio $\left(85 \% \mathrm{~K}_{\text {limit }}\right)$ of 5.64 . After reducing the concentration of the corrosion and scale inhibitor to $6.0 \mathrm{mg} / \mathrm{L}$ and controlling the p-alkalinity of the water to be less than $1.0 \mathrm{mM}$ by adding sulfuric acid, the corrosion rate of TP316L stainless steel was determined to be $0.0008 \mathrm{~mm} / \mathrm{a}$ as calculated by Equation (2) at a safety concentration ratio $\left(85 \% \mathrm{~K}_{\text {limit }}\right)$ of 9.27 . Under such conditions, no significant corrosion would occur on stainless-steel equipment [15]. 
Table 5. The results of scale-inhibition reduction test.

\begin{tabular}{ccccccc}
\hline $\begin{array}{c}\text { Operating } \\
\text { Conditions }\end{array}$ & $\mathbf{K}_{\text {limit }}$ & $\mathbf{8 5 \% \mathbf { K } _ { \text { limit } }}$ & $\begin{array}{c}\mathrm{Cl}^{-} \text {limit } \\
(\mathbf{m g} / \mathbf{L})\end{array}$ & $\begin{array}{c}\mathrm{Ca}^{2+}{ }_{\text {limit }} \\
(\mathbf{m g} / \mathbf{L})\end{array}$ & $\mathbf{\Delta B}$ & Control Conditions \\
\hline 1 & 6.64 & 5.64 & 146 & 52.99 & 0.19 & $\begin{array}{c}\text { Scale inhibitor } \\
\text { concentration }=8.5 \mathrm{mg} / \mathrm{L} \\
\text { Scale inhibitor }\end{array}$ \\
2 & 10.91 & 9.27 & 240 & 91.18 & -0.18 & $\begin{array}{c}\text { concentration }=6.0 \mathrm{mg} / \mathrm{L}, \\
\text { p-alkalinity } \leq 1.0 \mathrm{mM}, \\
\text { controlled by adding acid }\end{array}$ \\
\hline
\end{tabular}

According to these test results and upon combining them with the actual operation conditions on site, it is suggested to adopt the second set of operating conditions listed in Table 5. Under these conditions, the concentration ratio of the circulating water can be increased to 9.20 , and the dosage of the scale inhibitor can be reduced by $30 \%$.

\subsubsection{Impact of High Concentration Ratio on Promoting Zero Emissions in the Entire Plant}

The ultimate goal of increasing the concentration ratio of the circulating water system in the power plant is to save water and achieve zero wastewater discharge. The amount of fresh water replenished to and the amount of wastewater discharged from the circulating water when using different concentration ratios can be obtained by calculating the volume of water in the circulating water system under different conditions, as shown in Figure 7. It can be seen from the figure that under the current working conditions (with a concentration ratio of 4.5 for the circulating water) in the Dingzhou Power Plant, the amount of water replenished to and the amount of wastewater discharged from the circulating water system are $1200 \mathrm{~m}^{3} / \mathrm{h}$ and $199 \mathrm{~m}^{3} / \mathrm{h}$, respectively. When the concentration ratio was increased to 9.2, the amount of water replenished to and the amount of wastewater discharged from the circulating water system became $1050 \mathrm{~m}^{3} / \mathrm{h}$ and $49 \mathrm{~m}^{3} / \mathrm{h}$, respectively. Both the amount of replenishing and discharging water were reduced by $150 \mathrm{~m}^{3} / \mathrm{h}$. In addition, the total volume of wastewater discharged from the circulating system was reduced to $49 \mathrm{~m}^{3} / \mathrm{h}$, which can be fully treated by the desulfurization system. Therefore, no wastewater would be discharged into the environment.

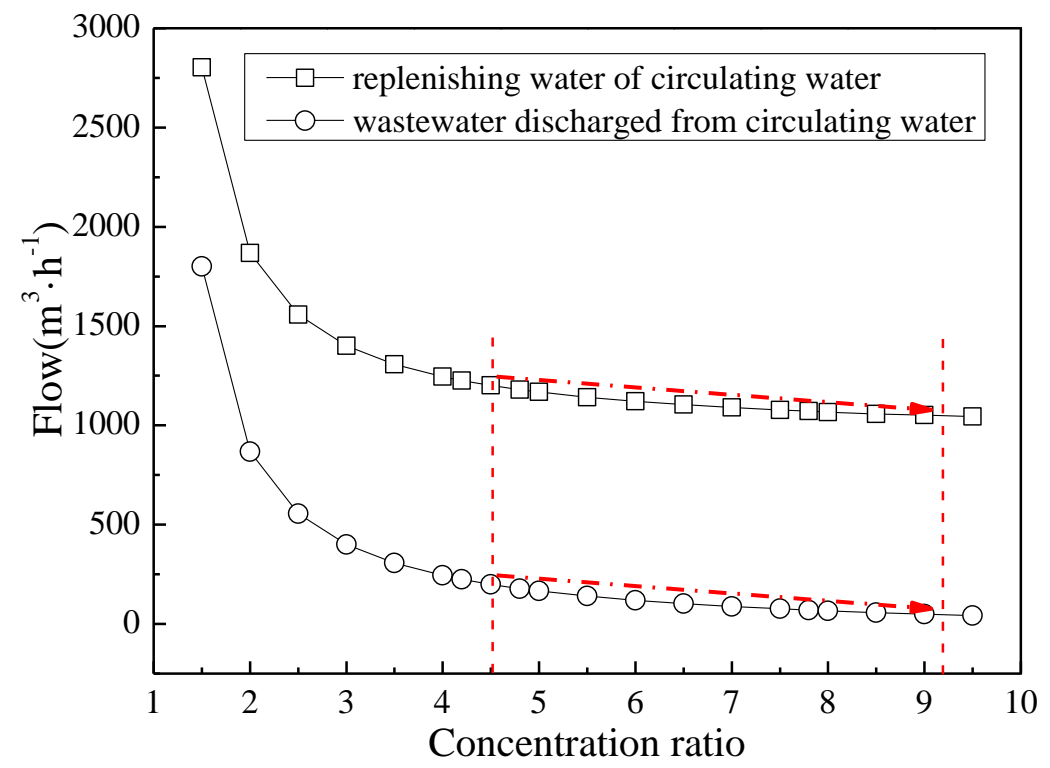

Figure 7. Amount of water replenished to and amount of wastewater discharged from the circulating water system for different concentration ratios. 


\subsection{Evaluation of Economic and Environmental Benefits of CPFBs System}

Increasing the concentration ratio of the circulating water can greatly reduce freshwater consumption and alleviate water stress in the local area. Reducing the waste content discharged from the circulating water system can be an effective approach to achieving zero liquid discharges and therefore reducing environmental pollution. In addition, the reduction of the required dosage of scale inhibitor in the circulating water can simplify the subsequent processes required to handle materials that are difficult to treat using scale inhibitors (such as phosphorus). Meanwhile, a reduction in the use of scale inhibitors also helps to protect the environment [24]. Through a comprehensive calculation, we found that Dingzhou Guohua Power Generation Co., Ltd. can save up to approximately 200,000 US dollars (US\$) per year after increasing the concentration ratio of the circulating water using the crystallization softening system (as shown in Table 6). Therefore, the proposed softening technology can provide significant economic and environmental benefits.

Table 6. Evaluation of the economic benefits (US dollars).

\begin{tabular}{|c|c|c|c|c|c|}
\hline Number & Indicator & Quantity & Unit Cost & $\begin{array}{l}\text { Economic Benefit } \\
\text { (dollars per year) }\end{array}$ & Note \\
\hline 1 & $\begin{array}{l}\text { Reduction in replenishing } \\
\text { water }\left(\mathrm{m}^{3} / \mathrm{h}\right)\end{array}$ & 150 & $\$ 0.398$ per $\mathrm{m}^{3}$ & 480977 & $\begin{array}{l}\text { Operating for } \\
335 \text { days a year }\end{array}$ \\
\hline 2 & $\begin{array}{l}\text { Reduction in waste } \\
\text { discharge }\left(\mathrm{m}^{3} / \mathrm{h}\right)\end{array}$ & 150 & $\$ 0.072$ per $\mathrm{m}^{3}$ & 87134 & $\begin{array}{l}\text { Operating for } \\
335 \text { days a year }\end{array}$ \\
\hline 3 & $\begin{array}{c}\text { Reduction in scale } \\
\text { inhibitor dosage (mg/L) }\end{array}$ & 2.5 & $\$ 1.156$ per ton & 22499 & $\begin{array}{c}\text { Average water } \\
\text { usage rate }= \\
1000 \mathrm{~m}^{3} / \mathrm{h}\end{array}$ \\
\hline 4 & $\begin{array}{l}\text { Amount of water } \\
\text { replenished to the } \\
\text { circulating water }\left(\mathrm{m}^{3} / \mathrm{h}\right)\end{array}$ & 1050 & $\$ 0.072$ per $\mathrm{m}^{3}$ & 390150 & $\begin{array}{c}\text { Current real } \\
\text { water volume } \\
6,722,400 \mathrm{~m}^{3} / \mathrm{y}\end{array}$ \\
\hline 5 & Cost savings per year & & & 200459 & \\
\hline
\end{tabular}

\section{Conclusions}

(1) The application of circulating pellet fluidized beds to soften the circulating water in the Dingzhou Power Plant results in a hardness removal rate of $40 \%-50 \%$ and a $\mathrm{Ca}^{2+}$ ion removal of $90 \%$, both of which ensure stable quality of the softened water. In addition, $\mathrm{CaO}$ contents in the discharged particles are greater than $50 \%$, which allows these particles to be used directly in the desulfurization system in the power plant. Therefore, no wastewater or waste solids are generated from the entire system.

(2) By pretreating the water via the use of circulating pellet fluidized beds and by discharging it into the circulating water system in the Dingzhou Power Plant, the concentration ratio of the circulating water is increased from 4.5 to 9.2 , the amount of replenishing water and wastewater discharges are both reduced by $150 \mathrm{~m}^{3} / \mathrm{h}$, and the dosage of the scale inhibitor is reduced by more than $30 \%$.

(3) The application of the circulating crystallization pellet fluidized bed system to soften the circulating water in the Dingzhou Power Plant reduces the cost of treating the circulating water to only $0.072 \mathrm{US} \$ / \mathrm{m}^{3}$. The power plant can thus save as much as 200,000 dollars per year. Therefore, the proposed softening technology can provide significant economic, environmental, and social benefits.

Author Contributions: R.H., T.H., T.W., H.W. and X.L. worked together; investigation, H.W.; methodology, X.L.; project administration, T.H. and T.W.; supervision, T.H.; writing (original draft), R.H.; writing (review and editing), R.H.

Funding: This research was funded by The National Key Research and Development Program of China (2016YFC0400706).

Conflicts of Interest: The authors declare no conflict of interest. 


\section{References}

1. Shao, W.; Feng, J.; Liu, J.; Yang, G.; Yang, Z.; Wang, J. Research on the Status of Water Conservation in the Thermal Power Industry in China. Energy Procedia 2017, 105, 3068-3074. [CrossRef]

2. Zhai, H.; Rubin, E.S.; Versteeg, P.L. Water Use at Pulverized Coal Power Plants with Postcombustion Carbon Capture and Storage. Environ. Sci. Technol. 2011, 45, 2479-2485. [CrossRef] [PubMed]

3. Zhang, X.; Liu, J.; Tang, Y.; Zhao, X.; Yang, H.; Gerbens-Leenes, P.W.; van Vliet, M.T.H.; Yan, J. China's coal-fired power plants impose pressure on water resources. J. Clean. Prod. 2017, 4, 1-9. [CrossRef]

4. Regucki, P.; Lewkowicz, M.; Krzyżyńska, R.; Jouhara, H. Numerical study of water flow rates in power plant cooling systems. Therm. Sci. Eng. Prog. 2018, 7, 27-32. [CrossRef]

5. Yi, L.; Jiao, W.; Chen, X.; Chen, W. An overview of reclaimed water reuse in China. J. Environ. Sci. 2011, 23, 1585-1593. [CrossRef]

6. Rahmani, K. Reducing water consumption by increasing the cycles of concentration and Considerations of corrosion and scaling in a cooling system. Appl. Therm. Eng. 2017, 114, 849-856. [CrossRef]

7. Ochoa, N.; Baril, G.; Moran, F.; Pébère, N. Study of the properties of a multi-component inhibitor used for water treatment in cooling circuits. J. Appl. Electrochem. 2002, 32, 497-504. [CrossRef]

8. Rahmani, K.; Jadidian, R.; Haghtalab, S. Evaluation of inhibitors and biocides on the corrosion, scaling and biofouling control of carbon steel and copper-nickel alloys in a power plant cooling water system. Desalination 2016, 393, 174-185. [CrossRef]

9. Vahedi, A.; Gorczyca, B. Application of fractal dimensions to study the structure of flocs formed in lime softening process. Water Res. 2011, 45, 545-556. [CrossRef] [PubMed]

10. O’Donnell, A.J.; Lytle, D.A.; Harmon, S.; Vu, K.; Chait, H.; Dionysiou, D.D. Removal of strontium from drinking water by conventional treatment and lime softening in bench-scale studies. Water Res. 2016, 103, 319-333. [CrossRef] [PubMed]

11. Hu, R.; Huang, T.; Zhi, A.; Tang, Z. Full-Scale Experimental Study of Groundwater Softening in a Circulating Pellet Fluidized Reactor. Intern. J. Environ. Res. Public Health 2018, 15, 1592. [CrossRef] [PubMed]

12. Hu, R.Z.; Huang, T.L.; Wen, G.; Yang, S.Y. Modelling particle growth of calcium carbonate in a pilot-scale pellet fluidized bed reactor. Water Sci. Technol. Water Supply 2016, 17, 643-651. [CrossRef]

13. Tang, Z.C.; Huang, T.L.; Hu, R.Z.; Zhang, R.F. Experimental study on softening high permanent hardness water in thermal power plants by induced crystallization. Water Treat. Technol. 2019, 45, 33-37, 46.

14. HG/T 2160-2008. Dynamic Simulation Test Method for Cooling Water; Chemical Industry Press: Beijing, China, 2008.

15. GB/T50050-2017. Code for Design of Industrial Circulating Cooling Water Treatment; Planning Publishing House: Beijing, China, 2017.

16. GB/T18175-2014. Determination of Corrosion Inhibition Performance of Water Treatment Agents-Rotation Specimen Method; Standards Publishing House: Beijing, China, 2014.

17. Jiang, K.; Zhou, K.G.; Yang, Y.C.; Du, H. Growth kinetics of calcium fluoride at high supersaturation in a fluidized bed reactor. Environ. Technol. 2014, 35, 82-88. [CrossRef] [PubMed]

18. Tai, C.Y. Crystal growth kinetics of two-step growth process in liquid Fluidized-bed crystallizers. J. Cryst. Growth 1999, 206, 109-118. [CrossRef]

19. Schetters, M.J.A.; Van Der Hoek, J.P.; Kramer, O.J.I.; Kors, L.J.; Palmen, L.J.; Hofs, B.; Koppers, H. Circular economy in drinking water treatment: Reuse of ground pellets as seeding material in the pellet softening process. Water Sci. Technol. A J. Int. Assoc. Water Pollut. Res. 2015, 71, 479. [CrossRef] [PubMed]

20. Scala, F.; Chirone, R.; Meloni, P.; Carcangiu, G.; Manca, M.; Mulas, G.; Mulas, A. Fluidized bed desulfurization using lime obtained after slow calcination of limestone particles. Fuel 2013, 114, 99-105. [CrossRef]

21. Chen, Y.; Fan, R.; An, D.; Cheng, Y.; Tan, H. Water softening by induced crystallization in fluidized bed. J. Environ. Sci. Engl. Ed. 2016, 50, 109. [CrossRef] [PubMed]

22. DB13T 2032-2014. Limestone Powder for Flue Gas Desulfurization (Wet Process); Hebei Quality and Supervision Bureau: Hebei, China, 2014. 
23. Liu, X.; Geng, M.; Zhou, S. Study on the scale and corrosion inhibitor of urban reclaimed water reused in circulating cooling water of power plant. In Proceedings of the 3rd International Conference on Energy Engineering and Environmental Protection, EEEP 2018, Sanya, China, 19-21 November 2018.

24. Xu, J.; Lin, K.; Huang, Y.; Guo, Q.; Li, H.; Yuan, D. Development of an online analyzer for determination of total phosphorus in industrial circulating cooling water with UV photooxidation digestion and spectrophotometric detection. Talanta 2019, 201, 74-81. [CrossRef] [PubMed]

(C) 2019 by the authors. Licensee MDPI, Basel, Switzerland. This article is an open access article distributed under the terms and conditions of the Creative Commons Attribution (CC BY) license (http://creativecommons.org/licenses/by/4.0/). 